\title{
Body mass index and nonalcoholic fatty liver disease
}

\author{
Shih-Wei Lai $\cdot$ Kuan-Fu Liao
}

Received: 21 September 2012/ Accepted: 24 October 2012/Published online: 17 January 2013

(C) Springer Japan 2013

To Editor,

We read one cohort study by Miyake and colleagues [1] showing that body mass index (BMI) is a useful factor for predicting the onset of nonalcoholic fatty liver disease (NAFLD). The optimal cutoff levels of BMI are $23 \mathrm{~kg} / \mathrm{m}^{2}$ for men and $22.2 \mathrm{~kg} / \mathrm{m}^{2}$ for women [1]. Similarly, in a cross-sectional study, we also found that subjects with BMI $\geq 27 \mathrm{~kg} / \mathrm{m}^{2}$ were at an increased risk of NAFLD (odds ratio $2.94,95 \%$ confidence interval 2.28-3.78, $P<0.001$ ), as compared with those with BMI $<27 \mathrm{~kg} / \mathrm{m}^{2}$ [2]. Because NAFLD could progress to advanced liver disease [3], it is relatively important to early identify individuals at risk of

An answer to this letter to the editor is available at doi: 10.1007/s00535-012-0735-4.

\section{S.-W. Lai}

School of Medicine, China Medical University,

Taichung, Taiwan

S.-W. Lai

Department of Family Medicine,

China Medical University Hospital,

Taichung, Taiwan

K.-F. Liao ( $\square)$

Department of Internal Medicine,

Taichung Tzu Chi General Hospital,

Taichung, Taiwan

e-mail: kuanfuliao@yahoo.com.tw

\section{K.-F. Liao}

Graduate Institute of Integrated Medicine,

China Medical University, Taichung, Taiwan

K.-F. Liao

Department of Health Care Administration, Central Taiwan University of Science and Technology,

Taichung, Taiwan developing NAFLD. BMI is an easily calculated tool in clinical practice. In our opinion, Miyake et al. and our studies have reported meaningful findings indicating that physicians can utilize BMI to identify, early on, individuals at risk of developing NAFLD in primary care settings.

Conflict of interest The authors disclose no conflicts of interest.

\section{References}

1. Miyake T, Kumagi T, Hirooka M, et al. Body mass index is the most useful predictive factor for the onset of nonalcoholic fatty liver disease: a community-based retrospective longitudinal cohort study. J Gastroenterol. 2012. doi:10.1007/s00535-012-0650-8.

2. Lai HC, Lin T, Lai SW, Liao KF. Association between nonalcoholic fatty liver disease and cardiovascular risk factors in a hospital-based study. Tzu Chi Med J. 2008;20:213-7.

3. Sugimoto K, Takei Y. Clinicopathological features of nonalcoholic fatty liver disease. Hepatol Res. 2011;41:911-20. 